\title{
Encompassing the Horse: Analogy, Category, and Scale in the Yijing
}

\author{
William Matthews \\ University College London
}

\begin{abstract}
The canonised Yijing had a decisive influence over the development of so-called "correlative cosmology" in China's early imperial period, presenting the cosmos as knowable through sixty-four hexagrams and classifiable according to eight trigrams. The exact nature of these correlative categories continues to inspire debate. On the one hand, they appear to be defined relationally, but on the other they purport to describe everything in the cosmos in terms of fixed principles. These apparently discordant properties can be reconciled by paying due attention to the role of scale. This is revealed through a focus on the hexagram images as two distinct but interrelated forms of analogy, as human constructs for symbolic manipulation and as empirical descriptors of cosmic circumstances. Adopting perspectives from cognitive linguistics and anthropology, this symbolic manipulation allows unknown situations to be understood metaphorically via the hexagrams, and then metonymically incorporated into a natural category of cosmic circumstances. This transition between metaphoric and metonymic relations is a function of scale, and is reflected in the Yijing's correlative categories. These correspond to perceived absolute natural kinds, but maintain a relational character dependant on the salience of metaphorical and metonymic relations at different scales.
\end{abstract}

Keywords: Yijing, cosmology, analogy, correlative thinking, early China, divination, scale, metaphor, metonymy.

To say that the Yijing 易經 had an instrumental influence over the development of Chinese cosmology from the time of the early empires is hardly controversial. However, the question of whether the way of ordering the world according to relational categories such as the Yijing's trigrams, yin and yang, and later the Five Phases-so-called "correlative cosmology"-constitutes something quite distinct from "Western" "causal" cosmological thinking remains subject to ongoing debate. ${ }^{1}$ This has led some Western scholars of early China to argue for fundamental differences between the two (Graham, 1989; Hall \& Ames, 1995; Ziporyn, 2012); others (notably, see chapter 5 of Lloyd, 1996), argue that maintaining such a distinction obscures the degree to which the two are interdependent. ${ }^{2}$ The problem arises from the fact that texts such as the Yijing group apparently disparate phenomena together-such as dogs, hands, and the Northeast-based on a logic which is not immediately obvious. Hence, David Hall and Roger Ames (1995) maintain that such groupings do not constitute "natural categories", and Brook Ziporyn (2012) contends that they are based on relational coherence rather than shared essence. Such arguments lead inevitably to a position that emphasises correlative categories as ways of ordering the world rather than descriptions of the way in which the world is (taken to be) ordered. As I show in this article, this position

\footnotetext{
This work was supported by the Economic and Social Research Council (grant number ES/J500185/1).

${ }^{1}$ Nylan (2010) provides an incisive review of both the evidence for correlative thought in early China, and uses of the term in the sinological and anthropological literature.

2 Similarly, I have argued elsewhere (Matthews, 2016) that "correlative thought" refers to at least three distinct ways of thinking.
} 
is problematic for the Yijing, given that the text unambiguously describes the world "as it is" and how it can be known.

However, it is possible to reconcile this with the relational character of the Yijing's correlative categories by paying attending to the status of analogy and scale within the text. Drawing on anthropological and cognitive linguistic approaches to analogy, metaphor, and metonymy, this article demonstrates that the Yijing's trigrams and hexagrams (three- and six-line diagrams that describe cosmic situations), can be understood both in terms of similarity (or resonance) and contiguity (or causal and part-whole relations). Which is salient is a function of scale, or of "zooming out" through the increasing levels of encompassment fundamental to this form of Chinese cosmology (Feuchtwang, 2014). I use "scale" here to refer to the scope of cosmological categories as indicated in the Yijing, from the scale of the cosmos as a whole, through to categories such as "animals", to far more specific scales such as varieties of horse. As I show, many beings cosmologically classified in the Yijing appear to belong to several categories, being classed under different trigrams. That is, they exist on several different taxonomic scales; which scale is relevant is a function of the comparative context in which a phenomenon is being considered. Hence, the Yijing's correlative categories are best understood, contra Hall and Ames, as "natural", but at the same time as encompassing phenomena across a wide range of cosmological scales. I begin with a brief overview of the Yijing's structure, before discussing its central concept of images (xiang 象) as two forms of analogy. I then examine how analogy is presented as an epistemological device in terms of metaphor and metonymy. Finally, this discussion is brought to bear on the nature of cosmological categories presented in the Yijing, and how these are affected by scale, with specific reference to the Shuogua 說卦 (Explaining the Trigrams).

\section{The Structure of the Yijing}

The Yijing is divisible into the Zhouyi 周易 and the Ten Wings (Shiyi 十翼). The former, its received form dating from the ninth century BCE (Rutt, 2002: 30-33; Shaughnessy, 1999), comprises the sixty-four hexagrams, their names, judgements on their meaning, and statements concerning their component lines (either broken or unbroken). Until the late Zhou the Zhouyi "was used exclusively for divination" (Smith, 2008: 7), not beginning to achieve its cosmological significance until the third century BCE and not yet incorporated into a correlative system (Shaughnessy, 1999: 341-342).

The Ten Wings comprise later commentaries appended to it to create the text canonised in 136 BCE as the Yijing. They date from the late first millennium BCE, and reinterpret the Zhouyi as a work of cosmology based on change and correlation, expanding its "divinatory potential" (Nylan, 2001: 233-252) in terms of the complementary principles of yin and yang. In considering "correlative cosmology", this article thus focuses on the canonised text of the Yijing, focusing especially on the Xiangzhuan 象轉 (Commentary on the Images), Tuanzhuan 彖轉 (Commentary on the Judgements), Xici 系辭 (Appended Phrases), and Shuogua. 


\section{The Role of Images as Two Kinds of Analogy}

The concept of the "image" (xiang 象) is central to the Yijing's approach to the relationship between human perception and the cosmos, appearing in the Xiangzhuan, Tuanzhuan, and Xici shang. The term "image" typically refers to the diagrams of each trigram and hexagram together with the phenomena associated with them, illustrated below for the hexagram Bo 剝, "Peeling". ${ }^{3}$

剝: 不利有敒往。

《彖》：剝，剝也，柔變剛也。不利有做往，小人長也。順而止 之, 觀象也。君子尚消息盈虛, 天行也。

《象》: 山附地上, 剝; 上以厚下, 安宅。

Bo: It is not beneficial to set forth.

Tuanzhuan: Bo, this is peeling. The weak transforms the strong. It is not beneficial to set forth, as the petty man is growing. To be compliant and restrain, this is to observe the image. The noble man esteems ebb and flow and waxing and waning; this is the movement of Heaven.

Xiangzhuan: The Mountain below and Earth above, Bo. Those above are magnanimous towards those below, and secure their residences.

Here, the Tuanzhuan elaborates the meaning of the hexagram name, the reference to "weak" (rou 柔) and "strong" (gang 剛) pertaining respectively both to the yin (broken) and yang (unbroken) lines of the hexagram and its constituent lower and upper trigrams; ${ }^{4}$ read in conjunction with the Xici, change is conceived as the complementary waxing and waning of yang and yin, strong and weak, Qian 乾 (extreme yang) and Kun 坤 (extreme yin). Hexagrams are read from bottom to top; here five yin lines precede a lone yang line, indicating yin's increasing prevalence and yang's complementary decline. Therefore, to "set forth" would be inauspicious, at odds with prevailing conditions, as yang is considered an initiating force (see Ziporyn, 2012: 238-243). An understanding of this image, in which the "weak" is effecting change, involves remaining "compliant" (shun 順). The image constitutes a conceptual means through which a person can understand a situation of the type Bo.

The Xiangzhuan describes the image of Bo based on the images of its component trigrams, comprising Kun 坤, the image of Earth (di 地), and below Gen 艮, the

\footnotetext{
${ }^{3}$ The primary text consulted is the Zhouyi zhengyi 周易正義 from the Wusyingdian shisan jing zhushu 武英殿十三經注疏, accessed via the Chinese Text Project (available on-line: http://ctext.org/bookof-changes, accessed 28.04.17). Hexagram and trigram names are translated following Richard Lynn (1994); though his work is based on a reading of Wang Bi's interpretation, this does not impact significantly on these names.

"Although the Tuanzhuan and Xiangzhuan primarily refer to the lines as "weak" and "strong", the term yang is also used to refer to the "strong" lines in the Xiangzhuan, and both terms are used in the Tuanzhuan, Wenyan, and Xici. As this article is concerned with a reading of the Yijing in toto, rather than the line texts alone, which predate this usage, yin and yang are used throughout.
} 
image of the Mountain (shan 山). This is presented alongside an analogical statement, "those above are magnanimous towards those below, and secure their residences", ${ }^{5}$ linking "those above" to Mountain, Gen, and "those below" to Earth, Kun. If "those above" are yang and active with respect to "those below", yin and receptive, the two are complementary. Thus, in spite of the dangers of initiating action, to embrace the situation as complementary (being "magnanimous to those below") is to be secure in one's position.

This form of analogical interpretation can be understood further with reference to the anthropologist Stanley Tambiah's (1985) distinction between "scientific predicative" and "conventional persuasive" analogies. The former serves as a model to generate hypotheses and comparisons verifiable through inductive reasoning. In his example (1985: 70), properties of light can be compared analogically with properties of sound, as shown below.

\begin{tabular}{|l|l|l|}
\hline & \multicolumn{2}{|c|}{ Similarity Relations } \\
\hline Causal Relations & Properties of Sound & Properties of Light \\
& Echoes & Reflection \\
& Loudness & Brightness \\
& Pitch & Colour \\
& Etc. & \\
\hline
\end{tabular}

Figure 1. A "scientific predicative" analogy between sound and light. Adapted from Tambiah (1985: 70).

Here, horizontal pairs (between individual or aggregate properties of sound and light) are similar, and vertical pairs (between properties within each vertical category) are causally related "in that certain properties are necessary or sufficient conditions for the occurrence of other properties" (1985: 70). Tambiah provides a second example based on horizontal similarities of structure and function and vertical relations of parts to wholes:

\begin{tabular}{|l|l|l|}
\hline & \multicolumn{2}{|c|}{ Similarity Relations } \\
\hline Co-occurrence & Bird & Fish \\
& Wings & Fins \\
& Lungs & Gills \\
& Feathers & Scales \\
\hline
\end{tabular}

Figure 2. A "scientific predicative" analogy based on structural and functional similarities between birds and fish. Adapted from Tambiah (1985: 70).

${ }^{5}$ 上以厚下, 安宅 
Such analogies allow predictions to be made regarding the constituents of one vertical category based on what is known of the constituents of the other, providing that "the vertical relations of the model are causal in some scientifically acceptable sense and if those of the explicandum also promise relations of the same kind, and if the essential properties and casual relations of the model have not been shown to be part of the negative analogy [i.e. the properties not shared by the two vertical categories] between model and explicandum" (Tambiah, 1985: 70, emphasis original). In principle, such predictions should be verifiable by observation.

Tambiah's "conventional persuasive" analogies are distinguished sharply from these. He gives the following example:

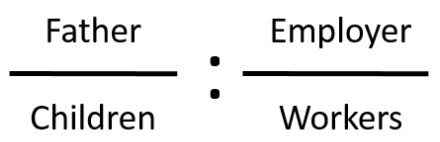

Figure 3. A "conventional persuasive" analogy between fathers and children and employers and workers. Adapted from Tambiah (1985: 71).

In this case, the analogy's purpose is to evoke rather than predict-for example, to persuade workers to hold certain attitudes to their employer. Here, "the vertical relations are not specifically causal" and there is no "relation of similarity between the terms, except by virtue of the fact that the two pairs are up to a point related by the same vertical relation" (Tambiah, 1985: 71, emphasis original). The analogy transfers the properties of the father-children relation to that of employer-workers. It is precisely this purpose of transfer rather than prediction that Tambiah argues characterises magical or symbolic action; for example, the use of the leaf-shedding Araka creeper as a leprosy treatment by the Azande people expresses the symbolic wish that the loss of extremities, analogous to the loss of leaves, be followed by growth rather than degeneration (1985: 73-74). Before applying this framework to the hexagram Bo, it is worth considering that whilst Tambiah's aim is to distinguish these two forms of analogy in order to elucidate the different purposes of scientific (causal) and magical (symbolic) thought and action, they are not mutually exclusive. Whilst the distinction is particularly illuminating, the Yijing's images can function as both, since they are dependent on scale.

The relevant form of analogy results from how far the hexagram is considered to yield an answer to the question of what should be done as opposed to the question of what will happen (Curry \& Wallis, 2004: 57), the first of which may be considered symbolic action, and the second, cosmological in scale, causal. The Zhouyi judgement for the hexagram Bo can be read as advice on proper course of action: "it is not beneficial to set forth". ${ }^{6}$ Likewise, the Tuanzhuan commentary, "to be compliant and restrain, this is to observe the image", 7 reads similarly as suggested action. Thus, the image of Bo can be schematised as the following "conventional persuasive" analogy:

\footnotetext{
${ }^{6}$ 不利有做往

7 順而止之, 觀象也
} 


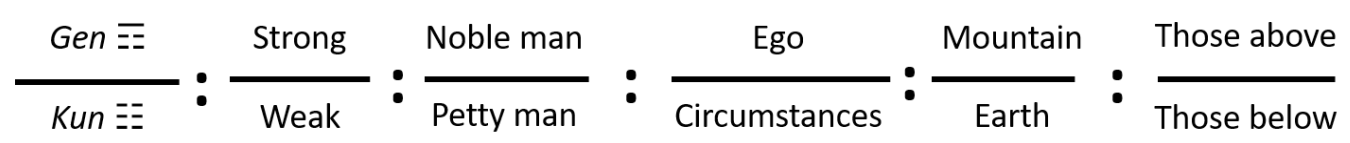

Figure 4. The hexagram image Bo as a "'conventional persuasive' persuasive" analogy.

Here, the five pairs of contrasts made in the Tuanzhuan and Xiangzhuan are presented alongside the hexagram's constituent trigrams, Gen and Kun. The similarities posited between horizontal elements stem from their shared vertical relation. The predominance of yin leads a yang process of initiating action to be undesirable. This is described in the text in terms of the "strong" (yang) being caused to change by the "weak" (yin), their relationship being comparable to that between a "noble man" (junzi 君子) when the "petty man is growing". ${ }^{8}$ The relationship between ego, who "observes the image" (guan 觀), and their circumstances is similar. Within the Tuanzhuan passage, the enquirer (ego) is related to circumstances in a manner akin to the relation between the "strong" and the "weak". The noble man complies with circumstances, here the "growing" of the "petty man", as the "strong" is caused to change by the "weak". Ego is thus advised to transfer the properties of the vertical relationships strong/weak and noble man/petty man to his own relationship with his circumstances. In the Xiangzhuan entry, the image of $B o$ is identified with the vertical relationship between Mountain (Gen) and Earth (Kun). The ability of "those above" to "secure their residences" is presented as a direct function of their ability to transfer the properties of the vertical relationship between Mountain and Earth to their own vertical relationship with "those below".

However, whilst this understanding of the image as a conventional persuasive analogy may be considered a proximate motivator to action on the part of ego, a consultor of the Yijing, the relationships between vertical pairs are open to further interpretations. Most obvious is that the vertical pairs strong/weak and noble man/petty man in the Tuanzhuan text for Bo describe a prevailing situation denoted by the hexagram, itself constituted by the vertical pair Mountain/Earth or Gen/Kun. The actions taken by ego in relation to circumstances, or "those above" in relation to "those below", are appropriate precisely because of the situation described by the other vertical pairs. Therefore, the petty man growing can be considered a phenomenon co-occurrent with "the weak transform[ing] the strong". In this sense, a causal relation exists between the vertical pairs strong/weak and noble man/petty man, changing the nature of the analogy between them. Moreover, the vertical pair those above/those below in the Xiangzhuan text may be considered similarly causally related. If "those above" are to "secure their residences", then a particular course of action must be taken, which is causally related to the vertical pairs strong/weak and noble man/petty man. In fact, it can be predicted based on the vertical relationships of the latter two pairs. This similarly applies to ego's relationship with circumstances if ego wishes to achieve an auspicious outcome.

\footnotetext{
8 小人長也
} 
Considered this way, the pairs comprising the image of Bo can be schematised as a "scientific predicative" analogy:

\begin{tabular}{|l|l|l|}
\hline & \multicolumn{2}{|c|}{ Similarity Relations } \\
\hline Co-occurrence & Kun & Gen \\
& Earth & Mountain \\
& Weak & Strong \\
& Petty man & Noble man \\
& Those below & Those above \\
& Circumstances & Ego \\
\hline
\end{tabular}

Figure 5. The hexagram image Bo as a "scientific predicative" analogy.

Considering both forms of analogy, whilst ego's motivation to normative action (what should be done to achieve an optimum outcome) may be proximately derived (as advice) from a conventional persuasive analogy, in which the properties of the vertical relations between strong/weak, noble man/petty man, and Mountain/Earth are transferred to the relation between ego and circumstances, ultimately the specific properties of that normative action can be predicted based on the cooccurring or causal relations between the remaining pairs. When presented in this way, the component trigrams Gen and Kun, and their images Mountain and Earth, appear not as symbolic referents for normative action but as categories of phenomena, like the properties of sound and light in Tambiah's example. Moreover, whilst the similarity between the vertical relations of the conventional persuasive analogy is retained, a second axis of similarity has been introduced. Whilst Kun and Gen (as trigrams) or "petty man" and "noble man" (as types of person) retain their relationship of similarity, a new, necessary similarity has been introduced between Kun and "petty man" and Gen and "noble man". Considering the images in this way demonstrates that an understanding of them as scientific predicative analogies requires integrating the hexagrams into a conception of yin and yang as cosmic forces.

\section{Analogy in the Epistemology of the Xici}

The role of images in the cosmology of the Ten Wings is made explicit in the Xici, though it should be borne in mind that this text, like the rest of the Ten Wings, represents later interpretations of the original symbols and cannot be taken as a reliable account of their original meaning. In the Xici shang, section one, ${ }^{9}$ the images are described as the product of things coming together according to kind:

方以類聚, 物以群分, 吉凶生矣。在天成象, 在地成形, 變化見 矣。

\footnotetext{
${ }^{9}$ Sections of the Xici are numbered following Lynn (1994).
} 
The tendencies [of affairs] group according to kind, and things divide according to their groups; thus arise the auspicious and harmful. In Heaven this process creates images, and on Earth it creates forms; thus transformation and permutation arise.

Here, images are situated as Heavenly (Tian 天) counterparts to Earthly Forms (Xing 形). Elsewhere in the Xici shang, section twelve, these terms are described as follows: "what is visible is called an image, what has physical form is called an object" (Nielsen, 2003: 277). ${ }^{10}$ Transformation and permutation (bianhua 變化) are visible through image and Form, and overall, the Yijing holds that Forms may be classified according to trigram and hexagram images. In section eleven of the Xici shang, images are granted implicit priority as the observable aspect of change:

一闔一闢謂之變; 往來不窮謂之通; 見乃謂之象。

A closing [followed by] an opening is called "transformation". Coming and going without exhaustion is called coherence and fluency. When it is seen, it is called the images.

Indeed, the association of Heaven with image and Earth with form is itself an example of this, Heaven and Earth being identified with the prototypical hexagrams Qian and Kun respectively; the Heavenly images and Earthly forms themselves exist in a process of change, perceptible as images. Without this conception of images as the percepts of groupings of natural kinds, hexagram images would cease to function as scientific predicative analogies and lose their predictive power.

The Xici describes the creation of the hexagram images and their role in terms of analogy, including through the use of the character $n i$ 擬, meaning to be similar or analogous to or to imitate or simulate. This character appears in both parts of the Xici. Section eight of the Xici shang describes the creation of the hexagram images by the "sages" (shengren 聖人) based on their observations of the phenomenal world:

聖人有以見天下之賾，而擬諸其形容，象其物宜，是故謂之象。 聖人有以見天下之動, 而觀其會通, 以行其典禮。繫辭焉, 以斷 其吉凶，是故謂之爻。言天下之至賾，而不可惡也。言天下之至 動，而不可亂也。擬之而後言，議之而後動，擬議以成其變化。

The sages had the means to observe the mysteries of all under Heaven, and drawing analogies ( $n i$ 擬) from their appearances, made suitable images of things, which are therefore called the images. The sages had the means to observe the motions of all under Heaven, and watched their gathering and communion, in order to bring out the standards of behaviour appropriate to each. They appended phrases to determine the auspicious and harmful, which were therefore called the interpretations (yao 爻). Speaking of the greatest mysteries under

${ }^{10}$ 見乃謂之象形乃謂之器 
Heaven, they cannot be odious. Speaking of the motions of all under Heaven, they cannot be disordered. To draw analogies [first] and speak afterward, to deliberate [first] and move afterward, it is in such drawing of analogy and [subsequent] deliberation that the transformation and permutation of things is successful.

In this account, images are derived in response to the problem of understanding the "mysteries of the world". ${ }^{11}$ This problem is solved by the sages' ability to know the world via analogy ( $n i$ 擬); the mysteries are perceived, their appearances used as a basis for comparison with other things, and from these analogically suitable things, the images are derived. Observing the processes of the world, the sages "[brought] out the standards of behaviour appropriate to each"; ${ }^{12}$ their ability to do so depended on an understanding of "the auspicious and harmful" (jixiong 吉凶). Describing how the sages used this to derive the "interpretations" (yao 爻) of the hexagrams, the text again acknowledges the value of analogy, embodied in the hexagram images, in understanding and operating effectively in the world; the interpretations' exegesis of these images allows understanding of "the greatest mysteries under Heaven". ${ }^{13}$ The first step in making sense of the cosmos is therefore to make comparisons using the images; only then can one "speak" (yan 言) of the phenomenon concerned, as it is through the images that knowledge of the world is acquired. Only after "deliberating" ( $y i$ 議) on this should one “move” (dong 動). Hence, there exists a sequence for ideal action by which "the transformation of things is successful": ${ }^{14}$ observation (jian 見) $\rightarrow$ comparison by analogy 擬 $\rightarrow$ deliberation 議 $\rightarrow$ action 動. As Michael Puett (2004: 188-196) argues, it is thus only via the system of the Yijing that the non-sage can know the world.

Puett further argues that the sages themselves are presented paradoxically not only as the creators of this epistemological system, but also as subservient to it (2004: 192-193). In the Xici xia section two, the sage-king Bao Xi, mythical creator of the trigrams, is presented "as purely an observer of patterns in the natural world" (2004: 192):

古者包犧氏之王天下也，仰則觀象於天，俯則觀法於地，觀鳥獸 之文, 與地之宜, 近取諸身, 遠取諸物, 於是始作八卦, 以通神 明之德，以類萬物之情。

In ancient times, Bao Xi ruled over the realm. Looking up, he observed the images in Heaven, and looking down he observed the patterns of Earth; he observed the patterns of birds and beasts and the features of the Earth. Nearby he drew from his body, and afar he drew from phenomena, and from this beginning created the Eight Trigrams, in

\footnotetext{
11 天下之賾

12 以行其典禮

${ }^{13}$ 天下之至賾

14 以成其變化
} 
order to commune with the virtues of the spirits and in order to classify the dispositions of the Ten Thousand Things.

This passage presents an important distinction not made explicit in the section just discussed, between the appearance of things ("images in Heaven", "patterns of birds and beasts" ${ }^{16}$ ) on the one hand, and "virtues of the spirits" 17 and the "dispositions of the Ten Thousand Things" ${ }^{18}$ on the other. The epistemological problem for Bao Xi is how to understand the latter when he can only perceive the former. The solution is a process of mediated analogical transfer; the known properties of appearances serve as a basis from which inherent qualities may be considered. However, a simple transfer of outward patterns to inward dispositions is inadequate. Rather, Bao Xi parses the appearances of things into a series of eight trigrams. It follows from this that the appearances of particular phenomena may be abstracted back from the trigrams, implying that they correspond to a more fundamental aspect of the cosmos. The eight trigrams therefore allow knowledge of that which is initially unknowable to human perception-the inherent virtues and dispositions of things.

The Yijing thus draws an epistemologically significant distinction between appearance and inner disposition. Knowledge of the former is available via human perception, but knowledge of the latter-full knowledge of the cosmos-requires the trigrams and hexagrams; Puett (2004: 188-196) makes a similar point. Moreover, both aspects of being are knowable via a single means, and for this to be valid the analogies drawn between the two aspects must be grounded in genuine similarity. Moreover, as Lisa Raphals (2013: 336-337) points out, the Yijing relies on "two parallel systems of signs", the cosmos itself and the Zhouyi. The foregoing discussion reveals that the images possess dual referents: phenomenal (occurrent in the cosmos) and symbolic (the human representation of a hexagram or trigram reified in the Zhouyi as a diagram). A hexagram image considered as a conventional persuasive analogy constitutes a symbolic construct providing a framework for normative action. An image considered as a scientific predicative analogy, in contrast, refers to a natural kind based on cosmic principles; it is a means of cosmological explanation. Likewise, considering Bao Xi's observations, the trigrams as facilitators of analogical transfer serve as symbolic constructs, but insofar as they are established as valid means of knowing the cosmos in all its aspects, they constitute referents to cosmic principles. Hereafter, I differentiate between these two usages with the terms trigrams/hexagrams-as-symbols or trigrams/hexagramsas-phenomena. In the next section, I expand this discussion into the realms of metaphor and metonymy.

\section{Hexagrams, Metaphor, and Metonymy}

\footnotetext{
15 象於天

16 鳥獸之文

17 神明之德

18 萬物之情
} 
The linguist Roman Jakobson (1956) describes an experiment in which young children are told to provide the first words they think of based on a stimulus word, in his example "hut", to which responses are of two kinds, "substitutive" (e.g. "cabin", "hovel") and "predicative" (e.g. "thatch", "poverty"), respectively manipulating connections of similarity and contiguity (1956: 76-77). The former constitute metaphoric responses, and the latter, metonymic; as James Fernandez (1986a: xii) puts it, metaphor concerns relations between domains and metonymy those within domains. I follow these definitions here, referring to generalised cognitive operations based on similarity and difference, rather than purely rhetorical devices.

As Jakobson argued, all symbolic processes, "either intrapersonal or social", involve both devices (1956: 80), but one or the other is likely to become prevalent. Anthropologists Deborah Durham and James Fernandez (1991) take this relationship further, arguing that metonymic association can follow as a result of metaphor. They define metaphors as operations of understanding a target domain by mapping onto it salient features of a source domain. Thus, for the hexagram Bo, ego's situation, as yet unknown, is knowable via the mapping onto it of the hexagram image. The function here is one of substitution of the image for the situation. However, following Durham and Fernandez, this metaphoric substitution draws together ego's situation and the hexagram Bo into a "more encompassing whole" (1991: 198) in which they are associated metonymically.

Following this understanding of the relationship between metaphor and metonymy, we can return to the fluidity of conventional persuasive and scientific predicative analogies discussed above. Taking Bo as an example, the transfer of relational properties from the vertical pair Mountain/Earth to noble man/petty man expresses a similarity of relations between the two. It is but a small step to then suggest that a genuine similarity exists between Mountains and noble men on the one hand and Earth and petty men on the other, in addition to, or stemming from, the similarity of vertical relations between the two pairs. Thus, an individual can consider it reasonable to make predictions regarding a noble man based on their knowledge of Mountains, quite apart from the similarity between the vertical relationships Mountain/Earth and noble man/petty man, within a certain type of situation. Thus, a series of conventional persuasive analogies can become a scientific predicative analogy, as demonstrated above. In such a case, the metaphoric relationship between Mountain and noble man or Earth and petty man, based on substitution of terms along the horizontal plane, becomes a relationship of metonymy. Mountain, noble man, those above, the strong, and so on, become a metonymic series of co-occurrent phenomena. This series, in the context of a hexagram image, is ultimately encompassed by the dyad Gen/Kun, the two components of which exist in dynamic relation. This dynamic dyad is accorded the label $B o$, itself thus constituting a metonymic category encompassing both vertical series shown in fig. 5 . However, this does not mean that metaphor has no place in the scientific predicative analogy; whilst elements within a column are metonymic (contiguous), they maintain metaphoric relationships with their counterparts in other columns. From the perspective of taxonomic structure, to understand the category Gen the known category Kun can be substituted, allowing an understanding 
of Gen as also referring to a metonymic class with elements of certain types (natural phenomena, material qualities, social positions, etc.).

A crucial question remains concerning the status of the vertical pair ego/circumstances in fig. 4. Whilst the hexagram and component trigram images may be unproblematically considered metonymic categories, this is not so straightforward for this pair. The hexagram image functions by persuading ego to adopt a relationship with circumstances analogous to that between the described dyads; this stems from an ability to predict the optimum relationship between ego and circumstances based on the remaining dyads. From the perspective of the Yijing as a complete account of the cosmos, at the beginning of the interpretive process all horizontal pairs in fig. 5 except ego/circumstances compose the metonymic categories Gen and Kun, together constituting the metonymic category Bo. These refer to a particular kind of situation, Bo-as-phenomenon, a dynamic composite of Gen-as-phenomenon and Kun-as-phenomenon taking the form of a scientific predicative analogy. Bo-, Gen-, and Kun-as-phenomenon are known domains. Consulting the Yijing, ego is interested in discovering appropriate action given her circumstances, a problem dependant on rendering these circumstances knowable in terms of an existing framework. The first operation she conducts is therefore one of metaphoric substitution; the known domain Bo-as-phenomenon (and its constituent trigrams-as-phenomena) is mapped onto the unknown domain of ego/circumstances. Now, the referent Bo-as-phenomenon is too complex for all its entailments to be meaningfully considered; ego's understanding of it is better facilitated by drawing on salient features, producing the mental representation Boas-symbol (the pair Gen-as-symbol/Kun-as-symbol). This is substituted for the mental construct ego/circumstances-as-symbol; this process consists in following a conventional persuasive analogy, as shown in fig. 4. Once this metaphoric substitution has been completed (via conventional persuasive analogy), ego/circumstances-as-phenomenon has been rendered knowable. This metonymically incorporates ego/circumstances-as-phenomenon into the category Bo-as-phenomenon (here a scientific predicative analogy). Cognitively, this has altered ego's understanding of both Bo-as-symbol and Bo-as-phenomenon, but in terms of cosmology, ego/circumstances-as-phenomenon is subsumed into an extant category of situations. I turn now to the implications of this analogical model for the trigram categories that are presented in the Shuogua.

\section{The Nature of Categories in the Shuogua}

Historically "extremely influential in the development of Han and later Chinese correlative metaphysics" (Redmond \& Hon, 2014: 254), the Shuogua presents a conception of the cosmos ordered according to the trigrams and their correlates. The trigrams are correlated with various aspects of the external world, including natural forms or phenomena, which constitute their primary associations (Heaven, Earth, Mountain, Lake, Thunder, Wind, Water, and Fire), cardinal directions, animals, body parts, horses, and kinship relations. Some of these associations are tabulated in 
fig. 6. Whilst these correlates constitute the main body of the text, it begins with a description of how the sages created the trigrams (sections one and two):

\section{昔者聖人之作《易》也，幽贊於神明而生著，參天兩地而倚數， 觀變於陰陽而立卦，發揮於剛柔而生爻，和順於道德而理於義， 窮理盡性以至於命。 \\ 昔者聖人之作《易》也，將以順性命之理，是以立天之道曰陰與 陽，立地之道曰柔與剛，立人之道曰仁與義。兼三才而兩之，故 《易》六畫而成卦。分陰分陽, 迭用柔剛, 故《易》六位而成章} $\circ$

In ancient times, when the sages made the Changes, [they did so] to participate profoundly in [that which is of] the spirits, they created the yarrow [as a means of divination]. Taking Heaven as three and Earth as two they brought the numbers into accordance. Observing the transformation of yin and yang they established the trigrams. Setting forth the movement of the strong and weak [hexagram lines] they created the interpretations [appended to the lines]. Complying with the Way and its virtue, they subjected things to a suitable principled order. Making full use of principle and the inner nature of things, they arrived at [an understanding of] fate.

In ancient times, when the sages made the Changes, they used it in order to comply with the principle inherent in inner nature and fate; it was to establish the Way of Heaven in terms of yin and yang, to establish the Way of Earth in terms of weak and strong, to establish the Way of Humanity in terms of benevolence and propriety. Bringing together the three capacities [Heaven, Earth, and Humanity] and doubling them, thus they took the six lines of the Changes and produced the hexagrams. Separating yin and yang, alternating between weak and strong, thus the six positions of the Changes produced models [of the cosmos, i.e. the hexagrams].

Section one establishes the cosmological validity of the trigrams by rooting their initial creation as symbols in sagely observation of the patterns of nature, as similarly described in the Xici shang. Here, though, the emphasis is less upon the analogical mapping of appearance onto inner nature than upon the trigrams as models of cosmic processes. Indeed, the purpose of the Zhouyi is here described as a means "to comply with the principle inherent in inner nature and fate". ${ }^{19}$ The trigrams thus not only allow an understanding of inner natures across space, but also an understanding of how these change over time; time and space are thus united via a common set of principles, the effects of which are elaborated in the hexagrams. This is seen in the very structure of the hexagrams, read as proceeding from bottom to top; as Lin (1995: 94-95) puts it, in the Yijing "the meaning of a time is a function of

${ }^{19}$ 以順性命之理 
[a hexagram line's] position, the significance of a position also depends on time. A certain position will be a place at a certain time."

It is likewise on the basis of this cosmological framework, "the Way and its virtue" (Daode 道德), that the observed world is to be classified according to a "principled order", ${ }^{20}$ li 理 being best understood as functioning as a verb ("to principle"). Yi 義, rendered here as "suitability", should be taken as the grounds upon which "principling" makes the most sense in light of cosmological knowledge. Implicit here is the tripartite conception of the cosmos comprising the realms of Heaven, Earth, and Humanity, made explicit in section two. Ziporyn (2012: 244) describes this as a "two-termed 'pendulum range' ... in three parallel realms", each of which has its own Dao or "course", the sustainability of which depends on a "dyadic alternation". Accordance with the inherent nature of things is thus presented as the pursuit of benevolence (ren 仁) and suitability ( $y i$ 義) in harmony with the ebb and flow of their Heavenly and Earthly counterparts, yin and yang and "weak" and "strong". Following Ziporyn, what I termed the "principling" of things consists in the emergence of coherence across the three realms. Each trigram thus expresses a particular configuration of these realms, and the six lines (two per realm) of a given hexagram correlate with the duality of yin and yang across the three. Again, the trigrams and hexagrams refer both to manipulable symbols and cosmic phenomena. As demonstrated by the further text of the Shuogua, the trigrams-as-phenomena may be understood as cosmic principles; the hexagrams, containing within them information concerning the three realms and both aspects of their dyads, may be understood as particular configurations of cosmic principles under specific spatiotemporal circumstances. The three realms can be understood as a scientific predicative analogy, in which optimum action in the Human realm can be determined based on the configurations of yin/yang and weak/strong in the Heavenly and Earthly realms. Again, knowing the appropriate human action requires a metaphoric operation in which the relationships between yin and yang and weak and strong are substituted for that between benevolence and suitability, but what constitutes appropriate human action is a metonymic function of the configuration of Heaven and Earth.

The character of trigrams-as-phenomena as cosmic principles is well-illustrated by sections three to five of the Shuogua:

天地定位，山澤通氣，雷風相薄，水火不相射，八卦相錯。數往 者順, 知來者逆, 是故《易》逆數也。

雷以動之, 風以散之, 雨以潤之, 日以烜之, 艮以止之, 召以說 [ 悅 yue $]$, 乾以君之, 坤以藏之。

帝出乎震, 齊乎巽, 相見乎離, 致役乎坤, 說[悅]言乎兌, 戰乎乾 , 勞乎坎, 成言乎艮。萬物出乎震, 震東方也。齊乎巽, 巽東南 也, 齊也者、言萬物之絜齊也。離也者、明也, 萬物皆相見, 南 方之卦也。聖人南面而聽天下, 㗽明而治, 蓋取諸此也。坤也者 、地也, 萬物皆致養焉, 故曰: 致役乎坤。兌、正秋也, 萬物之 
所說也, 故曰: 說[悅]言乎兌。戰乎乾, 乾、西北之卦也, 言陰陽 相薄也。坎者、水也, 正北方之卦也, 勞卦也, 萬物之所歸也, 故曰: 勞乎坎。艮、東北之卦也。萬物之所成終而所成始也。故 曰: 成言乎艮。

Heaven and Earth fix the positions, the Mountain and the Lake give passage to qi, Thunder and Wind press each other on, Water and Fire do not damage one another, the Eight Trigrams mutually alternate. That which reckons the past, proceeds, that which knows the future, recedes, thus the Changes enumerates in reverse.

Thunder is that which moves, Wind that which disperses, Rain [Water] that which moistens, the sun [Fire] that which dries, Gen [Mountain] that which restrains, Dui [Lake] that which pleases, Qian [Heaven] that which rules, Kun [Earth] that which harbours.

The thearch comes forth in Zhen, makes things uniform in Xun, [they] come into mutual contact in $L i$, [the thearch] delivers service in Kun, delights in Dui, contends in Qian, is rewarded in Kan, and reaches completion in Gen. The Ten thousand Things come forth in Zhen; Zhen is the East. They are made uniform in Xun; Xun is the Southeast. That which makes things uniform is called that which evenly delimits the Ten Thousand Things. $L i$ is brightness, is the mutual manifestation of all the Ten Thousand Things, is the trigram of the South. The sage faces south and heeds [the affairs of] the realm, governing towards brightness, whence this [idea] is doubtless derived. Kun is Earth, is where the Ten Thousand Things all derive nourishment; thus it is said, [the thearch] delivers service in Kun. Dui is the height of Autumn, is that which delights the Ten Thousand Things; thus it is said, [the thearch] delights in Dui. [The thearch] contends in Qian; Qian is the trigram of the Northwest, and is called the mutual pressing on of yin and yang. Kan is Water, is the trigram of true North, is the trigram of comfort, is that to which the Ten Thousand Things return; thus it is said, [the thearch] is rewarded in Kan. Gen is the trigram of the Northeast. It is where the Ten Thousand Things come to final completion and where they begin. Thus it is said, [the thearch] reaches completion in Gen.

Here, the trigrams are set out in sequence, suggesting a fundamental natural process of endless generation and regeneration (Redmond \& Hon, 2014: 150). Sections three and four refer to the trigrams metonymically via their associated natural phenomena. As Ziporyn (2012: 244-245) points out, section three presents the trigrams as four contrasting pairs with certain functions, and section four describes the specific function of each trigram-as-phenomenon. As he argues, the correlates of each trigram are not obviously derivable from the three-line symbols themselves, but many of them pertain to the natural phenomena outlined in sections three and four. Thus Water (i.e. the trigram Kan), referred to metonymically 
in section four as "rain" ( $y u$ 雨) which "moistens" (run 潤), in section seven is described as a "pitfall" or, in Ziporyn's translation, "danger" (xian 陷); as he argues, neither meaning is easily discernible from the trigram symbol, but both are properties of water. The Shuogua thus classifies various groups of experiential phenomena metonymically according to trigram. Some of these correlates are tabulated in fig. 6; the Shuogua goes on to list many more, including far more specific groups such as kinds of horse and qualities of tree.

\begin{tabular}{|c|c|c|c|c|c|c|c|c|}
\hline Trigram & Qian三 & Kun $\equiv$ & Gen $\Xi$ & Dui & Zhen $\equiv$ & Xun $\equiv$ & Kan $=$ & $L i \equiv$ \\
\hline $\begin{array}{l}\text { Natural } \\
\text { Form }\end{array}$ & $\begin{array}{l}\text { Heaven } \\
\text { 天 tian }\end{array}$ & $\begin{array}{l}\text { Earth } \\
\text { 地 } d i \\
\end{array}$ & $\begin{array}{l}\text { Mountain } \\
\text { 山 shan }\end{array}$ & $\begin{array}{l}\text { Lake } \\
\text { 澤 ze }\end{array}$ & $\begin{array}{c}\text { Thunder } \\
\text { 雷 lei }\end{array}$ & $\begin{array}{l}\text { Wind } \\
\text { 風feng }\end{array}$ & $\begin{array}{l}\text { Water } \\
\text { 水 shui }\end{array}$ & $\begin{array}{l}\text { Fire } \\
\text { 火 huo } \\
\end{array}$ \\
\hline Action & $\begin{array}{l}\text { Ruling } \\
\text { 君 jun }\end{array}$ & $\begin{array}{l}\text { Storage } \\
\text { 藏 cang }\end{array}$ & $\begin{array}{l}\text { Restraint } \\
\text { 止 zhi }\end{array}$ & $\begin{array}{l}\text { Pleasing } \\
\text { 說[悅] yue }\end{array}$ & $\begin{array}{l}\text { Setting in } \\
\text { motion } \\
\text { 動 dong }\end{array}$ & $\begin{array}{c}\text { Dispersal } \\
\text { 散 san }\end{array}$ & $\begin{array}{l}\text { Moistening } \\
\text { 潤 run }\end{array}$ & $\begin{array}{l}\text { Drying } \\
\text { 恒 heng }\end{array}$ \\
\hline Direction & $\begin{array}{l}\text { North- } \\
\text { west }\end{array}$ & $\begin{array}{l}\text { (South- } \\
\text { West) }\end{array}$ & Northeast & $\begin{array}{l}\text { (West; the } \\
\text { height of } \\
\text { autumn) }\end{array}$ & East & $\begin{array}{l}\text { South- } \\
\text { east }\end{array}$ & North & South \\
\hline Quality & $\begin{array}{c}\text { Strength } \\
\text { 健 jian }\end{array}$ & $\begin{array}{c}\text { Compliance } \\
\text { 順 shun }\end{array}$ & $\begin{array}{c}\text { Cessation } \\
\text { 止 zhi }\end{array}$ & $\begin{array}{c}\text { Delight } \\
\text { 說[悅] yue }\end{array}$ & $\begin{array}{l}\text { Energising } \\
\text { 動 dong }\end{array}$ & $\begin{array}{c}\text { Entering } \\
\text { 入ru }\end{array}$ & $\begin{array}{l}\text { Pitfall } \\
\text { 陷 xian }\end{array}$ & $\begin{array}{c}\text { Attachment } \\
\text { 麗 } / i\end{array}$ \\
\hline Animal & Horse & $O x$ & Dog & Sheep & Dragon & Chicken & Pig & Pheasant \\
\hline $\begin{array}{l}\text { Body } \\
\text { Part }\end{array}$ & Head & Stomach & Hand & Mouth & Foot & Thigh & Ear & Eye \\
\hline $\begin{array}{l}\text { Family } \\
\text { Member }\end{array}$ & Father & Mother & $\begin{array}{c}\text { Youngest } \\
\text { Son }\end{array}$ & $\begin{array}{l}\text { Youngest } \\
\text { Daughter }\end{array}$ & $\begin{array}{c}\text { Eldest } \\
\text { Son }\end{array}$ & $\begin{array}{c}\text { Eldest } \\
\text { Daughter }\end{array}$ & $\begin{array}{c}\text { Middle } \\
\text { Son }\end{array}$ & $\begin{array}{c}\text { Middle } \\
\text { Daughter }\end{array}$ \\
\hline
\end{tabular}

Figure 6. Selected correlates of the trigrams in sections four to nine of the Shuogua (translations following Lynn [1994: 121-123]).

So far, the discussion of metaphor and metonymy has focused on the interdependence of the two, and this is crucial for understanding the correlates laid out in the Shuogua. Relevant anthropological discussions, such as that by Edmund Leach (1976: 15), have argued that the designations "metaphor" and "metonymy" are approximately equivalent to symbol/sign, paradigmatic association/syntagmatic chain, and harmony/melody. Whilst this conception is valuable, it can obscure the degree to which relationships of metaphor and metonymy are functions of perspective and scale. Considering vertical categories in fig. 6, a Leach-inspired view of the table might conclude that the metaphorical relationship exists between a trigram-as-symbol and the members of its column, such that it may be substituted for them (Qian-as-symbol for Heaven, for example). Likewise, the relationship between any horizontal dyad may be substituted for its vertical counterparts (Heaven is to Earth as "ruling" is to "storage"); this may extend to the substitution of the relationships between the components of an entire row for those between the components of another (the relationships between all natural forms for the relationships between all actions, for example). This tells us about the relationship between members of experiential classes (i.e. classes of entities generally perceived as of a type, such as animals; rows in fig. 6), but not about the relationship between members of trigram classes (columns). To understand these, we must recognise that, from a taxonomic point of view, columns and vertical dyads may be similarly related metaphorically. Thus, Qian and all members of its class may substitute for Kun and 
all members of its class from the perspective of taxonomic structure, as in the scientific predicative analogy illustrated in fig.5. As such, relations of similarity may be found along both axes; vertically, similarities (and grounds for substitution) consist of an element's belonging to a trigram category (any Qian-Kun dyad can substitute for another, e.g. Heaven : Earth :: ruling : storage), and horizontally, similarities consist of elements belonging to an experiential category (e.g. Heaven : ruling :: Earth : storage).

However, the fact that the components of a given trigram column can be predicted by those of another indicates that, although Qian-as-symbol can substitute for any of the Qian column's elements, the relationship that exists within a column in fig. 6 is one of metonymy; that is, each column comprises a contiguous group composed of a natural form, an action, a direction, and so on. As such, following Fernandez (1986b: 44), the relationships within categories are akin to those between cause and effect and part and whole. Thus, the metonymic category Qian corresponds to Qian-as-phenomenon, a real-world class of co-occurrent phenomena, that is, a spatial metonymy. However, as has been seen the Shuogua also positions the trigrams in a sequence of generation and regeneration. This complicates the structure illustrated in fig. 6 further, indicating a temporal metonymy along the horizontal plane, analogous to melody but accompanied by metonymic continuity in the vertical (spatial) plane. This, though, takes us to a different scale, as the metonymic category on the horizontal plane comprises all eight trigrams, which on this level cease to be the relevant taxonomic category as they themselves represent stages of transformation of a larger category, the cosmos itself.

This speaks to a broader question of the role similarity and difference play in correlative cosmology. Whilst the Shuogua predates the wholesale adoption of a systematised cosmology based on universal qi constantly transforming in a cycle of Five Phases, it nonetheless illustrates the problem very effectively. Here, it is worth considering Ziporyn's (2012: 245-249) analysis of coherence in trigram categories. He argues that the horizontal categories tabulated in fig. 6 should be understood as "coherent wholes" each composed of eight points, which balance one another. These coherent wholes all follow analogous arrangements, and may contain within themselves other coherent wholes; the coherent whole of the animal kingdom, for example, contains the coherent whole "horses", different kinds of which are grouped according to the trigrams Qian, Zhen, and Kan in sections eleven, thirteen, and fifteen. Horizontal coherences, moreover, comprise groups which may be experienced as natural kinds. This much is not especially problematic.

The problem arises, as Ziporyn acknowledges, when we turn to the "vertical coherences". He argues that the trigram groups are based on "relations of parallelisms of position and function" (2012: 246, emphasis removed); among animals, for example, the ox is "compliant" and "earthlike" (easily domesticated and used to plough) and therefore Kun. Similar coherent relationships exist-or would have existed for the text's authors-between each element of a trigram category and the qualities of the trigram-as-phenomenon to which it is metonymically 
related. Ziporyn argues that whilst it may be tempting to then identify each member of a trigram category as instantiating a particular quality or essence, this is made problematic by nested coherences, such as that of horses within animals. Horses as animals are Qian, but a horse that is "good at neighing" (shan ming 善鳴) is Zhen. The question is whether the neighing horse is thus somehow both Qian and Kun, or whether, as Ziporyn argues, is a function of its horizontal coherence-Qian with respect to animals as a whole but Zhen with respect to horses as a whole. In this conception, "horses are not first Qianlike and then included in the class Qian. Rather, by being put into parallelism with other Qian items, and assuming a position within the coherent whole of the animal kingdom, horse [sic] manifests Qian-ness" (2012: 248). Ziporyn's argument opposes the notion of the trigrams somehow describing natural kinds, the members of which "instantiate a form of universal" (2012: 246); in his view, they are implicitly human-imposed terms describing relational properties which facilitate organising phenomena coherently. Regarding the trigrams, as he puts it, "sameness is a function of coherence, not the other way around" (2012: 247). Thus, the problem of correlative categories with which this article began. We are now in a position to address it in light of the foregoing discussion.

\section{A Relative Horse is an Absolute Horse}

The function of analogy and the interdependence of metaphor and metonymy across scales demonstrates that, contra Ziporyn, coherence is a function of scale, the categories of the Shuogua denoting natural kinds based on shared characteristics, which are nonetheless relationally defined with respect to scale. This is shown by the following three points. The first two concern the trigrams as human-imposed, but do not preclude their relational contingency, despite rendering it more complicated. The third concerns the knowability of the cosmos.

First, considered in terms of the account given in the Xici shang, the view of human-imposed relational categories is at odds with the description of the trigrams' derivation from direct observation of natural patterns and consequent accordance with cosmic principles. Even considered in relation to the Shuogua alone, it is undermined by the account given in sections one and two; if the movements of lines are derived from observations of the transformation of yin and yang, and the trigrams and hexagrams effectively accord with the inherent nature of things, then they must genuinely resemble natural kinds of phenomena.

Second, as the foregoing discussion of the hexagram Bo established, appropriate human action is predictable; it is hard to see how this could be tenable if a hexagram, and by extension its component trigrams, were not considered to accurately reflect the state of the cosmos at a given spatiotemporal juncture. Both of these objections assume that, for analogical reasoning to be practically effective (in the manner these accounts present it to be), on some level genuine similarity must exist between metonymically-related phenomena. That is, all situations denoted by a hexagram constitute a natural kind. 
Nonetheless, Ziporyn's point about trigram-ness being a function of context cannot be easily dismissed, especially when, as he points out, we consider the status of horses in the Shuogua. His point is similarly well-illustrated by his example of the trigram Dui, whose metonymic correlates include "delight", "sheep", and "mouth" (see fig. 6). He concludes that the connection between the three is not one of resemblance but of harmonisation; the three terms go together "because 'lamb' is 'pleasing' to the human 'mouth'" (Ziporyn, 2012: 247). These arguments suggest coherences nested across scales on the horizontal plane-hence a horse can be Qian in one category and Zhen in another, in each case being identified as such not because it has a Qian or Zhen essence (or is of a kind), but because by being placed in a particular configuration of entities it manifests Qian-ness or Zhen-ness (2012: 248). Thus, the horse is "only locally coherent", its "global coherence [being] restricted to seeing the totality [of all contexts] as a totality only, and in connection with the disambiguating decisions of the sages in making these particular connections" (2012: 248, emphasis original).

The third, and most significant, point is that whilst this is all well and good if we are concerned with human perception alone, the author(s) of the Shuogua were cosmologists whose concern was not simply describing relational properties but, as has been shown, knowing via the trigrams that which is unknowable to ordinary human perception. An obvious corollary of something unknowable to human perception is that, like the trigram categories, it may not make obvious sense, regardless of its actual correspondence with cosmic reality. None of Ziporyn's arguments-even that concerning the delights of lamb consumption-rules out the possibility that however bizarre the connections between trigram-category members may seem, the reason that trigram-category coherences work is that their members all share a set of common characteristics or embody a certain cosmic principle or configuration. Such a view implies a vertical nesting as well as a horizontal; that is, in addition to the nesting of, say, horses within animals, Qian can also be nested into Kun depending on the scale of the phenomenon being considered. Sections three to seven of the Shuogua describe a process of transformation, each phase of which is embodied in a trigram. If this is taken to work across scales, it follows that each phase of the cycle may be subdivided into analogous phases, such that phase Qian may proceed diachronically through stages of Zhen-ness, Xun-ness, Li-ness and so on. This view preserves both the relational properties of the trigrams and allows for their existence as cosmic principles. Our friends the horses thus take on a hierarchy of trigram-ness; as an animal, a horse embodies Qian-ness as an inherent characteristic, but this Qian-ness itself can be subdivided into Zhen-ness, Xun-ness and so on at different scales. Thus, considering a group of horses, whilst all are Qian entities, keeping in mind this Qian-ness stepping down a scale, those which are good at neighing possess a more Zhen-like Qian-ness (that is, their Qian-ness is constituted by a significant quantity of Zhen). Likewise, keeping in mind the metonymic character of each trigram category, this point may be phrased in terms of Zhen-asphenomenon causing good neighing in horses, and Qian-as-phenomenon producing horses among animals. Therefore, contra Ziporyn, a horse that neighs well is both Qian and Kun. The Qian-ness of all horses is simply irrelevant when considering a particular horse in relation to other horses; what is relevant is the particular trigram- 
ness of that Qian-ness. Trigram-ness is thus both absolute and a function of scale; exactly what scale of trigram-ness is relevant depends on the purposes of the observer.

\section{Conclusion}

The nested structure of trigram categories avoids the problem of reconciling their relational character with the fact that the Yijing is presented as a genuine account of cosmic principles. Moreover, this explanation is coherent with the epistemological status of the hexagrams as guides to effective action derived analogically from the observable world. Hexagrams themselves can be understood as both symbolic motivators to action as conventional persuasive analogies, and as scientific predicative explanations for why such action is appropriate. Hexagrams-as-symbols can be mobilised as conventional persuasive analogies in order to understand unknown situations, which are rendered knowable through metonymic incorporation into a natural category of tri/hexagram-as-phenomenon, defined in terms of a shared cosmic configuration.

Whilst trigrams may metaphorically substitute for any member of their correlative categories, and the relationship between analogous members of two or more categories may be metaphorically substituted for that between other analogous members of the same categories, members of a single trigram category are not related metaphorically but metonymically. However, from the point of view of taxonomy, the structure of any trigram category can be substituted for another. Members of a given trigram category share inherent characteristics, but from the perspective of an observer a phenomenon's relevant trigram-ness is a function of scale. A horse in the Yijing thus enjoys the privilege of being at once an absolute and relative expression of the cosmos through its different degrees of encompassment across scales.

\section{References}

Primary Source

Wang $\mathrm{Bi}$, Han Kangbo and Kong Yida, Zhouyi zhengyi (Correct interpretation of the Book of Changes), Chinese Text Project, available at: http://ctex t.org/book-ofchanges (accessed 28.04.17).

Secondary Sources

Curry, Patrick M. and Roy Wallis (2004), Astrology, Science and Culture: Pulling Down the Moon, Oxford: Berg. 
Durham, Deborah and James W. Fernandez (1991), "Tropical Dominions: The Figurative Struggle over Domains of Belonging and Apartness in Africa", 190-210, in James W. Fernandez (ed.), Beyond Metaphor: The Theory of Tropes in Anthropology, Stanford: Stanford University Press.

Fernandez, James W. (1986a), "Introduction", vii-xv, in Persuasions and Performances: The Play of Tropes in Culture, Bloomington: Indiana University Press.

- - (1986b), "The Mission of Metaphor in Expressive Culture", 28-70, in Persuasions and Performances: The Play of Tropes in Culture, Bloomington: Indiana University Press.

Feuchtwang, Stephan (2014), "Coordinates of Body and Place: Chinese Practices of Centring", 116-133, in Allen Abramson and Martin Holbraad (eds.), Framing Cosmologies: The Anthropology of Worlds, Manchester: Manchester University Press.

Graham, A. C. (1989), Disputers of the Tao: Philosophical Argument in Ancient China, La Salle, IL: Open Court.

Hall, David L. and Roger T. Ames (1995), Anticipating China: Thinking Through the Narratives of Chinese and Western Culture, Albany: State University of New York Press.

Jakobson, Roman (1956), "Two Aspects of Language and Two Types of Aphasic Disturbances", 53-82, in Roman Jakobson and Morris Halle (eds.), Fundamentals of Language, The Hague: Mouton \& Co.

Leach, Edmund (1976), Culture and Communication: The Logic by Which Symbols Are Connected, Cambridge: Cambridge University Press.

Lin, Li-Chen (1995), "The Concepts of Time and Position in the Book of Change and Their Development", trans. by Kirill Ole Thompson, 89-113, in Chün-chieh Huang and Erik Zürcher (eds.), Time and Space in Chinese Culture, Leiden: Brill.

Lloyd, G. E. R. (1996), Adversaries and Authorities: Investigations into Ancient Greek and Chinese Science, Cambridge: Cambridge University Press.

Lynn, Richard John (1994), The Classic of Changes: A New Translation of the "I Ching" as Interpreted by Wang Bi, New York: Columbia University Press.

Matthews, W. E. (2016), "The Homological Cosmos: Ontology, Epistemology, and Ethics in Yi Jing Prediction", unpublished PhD thesis, University College London.

Nielsen, Bent (2003), A Companion to Yi Jing Numerology and Cosmology. London: Routledge.

Nylan, Michael (2001), The Five Confucian Classics, New Haven: Yale University Press.

- - (2010), "Yin-yang, Five Phases, and Qi", 398-414, in Michael Nylan and Michael Loewe (eds.), China's Early Empires: A Re-appraisal, Cambridge: Cambridge University Press.

Puett, Michael J. (2004), To Become a God: Cosmology, Sacrifice, and SelfDivinization in Early China, Cambridge, Mass.: Harvard University Press.

Raphals, Lisa (2013), Divination and Prediction in Early China and Ancient Greece, Cambridge: Cambridge University Press.

Redmond, Geoffrey and Tze-Ki Hon (2014), Teaching the I Ching (Book of Changes), Oxford: Oxford University Press.

Rutt, Richard (2002), Zhouyi: The Book of Changes, London: Routledge. 
Shaughnessy, E. L. (1999), "Western Zhou History", 292-351, in Michael Loewe and Edward L. Shaughnessy (eds.), The Cambridge History of Ancient China: From the Origins of Civilization to 221 B.C., Cambridge: Cambridge University Press.

Smith, Richard J. (2008), Fathoming the Cosmos and Ordering the World: The Yijing (I-Ching, or Classic of Changes) and Its Evolution in China, Charlottesville: University of Virginia Press.

Tambiah, Stanley Jeyaraja (1985), "Form and Meaning of Magical Acts", 60-86, in Culture, Thought, and Social Action: An Anthropological Perspective, Cambridge, Mass: Harvard University Press.

Ziporyn, Brook (2012), Ironies of Oneness and Difference: Coherence in Early Chinese Thought; Prolegomena to the Study of Li, New York: State University of New York Press.

William Matthews received his PhD in Anthropology from UCL in 2016, for which he focused on analogical reasoning in Yijing cosmology. 